\title{
Antibiotic therapy, clinical features and outcome of 36 adults presenting to hospital with proven influenza: do we follow guidelines?
}

\author{
Adrian Jones, John Macfarlane and Simon Pugh ${ }^{1}$
}

\author{
Respiratory Medicine and ${ }^{1}$ Department of Microbiology and Public Health Laboratory, City Hospital, \\ Nottingham NG5 IPB, UK
}

\begin{abstract}
Summary: The impact of the 1989/1990 influenza epidemic on the Nottingham hospitals was assessed in a retrospective survey. Thirty-six cases of proven influenza were identified, 14 of whom died. Non-survivors were more likely to be confused, uraemic and to lack focal chest signs and symptoms. Antibiotic therapy both prior to admission and following hospitalization was not optimal and, in many cases, failed to follow previously published guidelines. Such guidelines need emphasis during influenza epidemics.
\end{abstract}

\section{Introduction}

The influenza epidemic over the winter $1989 / 1990$ was a source of great stress on medical services because of the marked rise in illness amongst the general population as well as hospital staff. Estimates of the increased mortality attributable to the epidemic have suggested that, although only 2440 deaths were certified as due to influenza, 26080 excess deaths occurred during this same period in England and Wales. ${ }^{1}$ In order to characterize the features of adults presenting to hospital and their subsequent management during such an epidemic, we conducted a retrospective survey of proven cases of influenza.

\section{Methods}

Between 11th November 1989 and 11th January 1990,107 cases of influenza were diagnosed by the Nottingham Public Health Laboratory Service. We have studied the case records of 36 adults who presented to hospital. The diagnosis of influenza virus infection required one or more of the following criteria: (a) isolation of the virus from throat swab, respiratory secretions or tissue; (b) identification of the virus by specific direct fluorescent antibody staining; (c) a four fold rise in influenza antibodies as demonstrated by complement fixation test or a single titre $\geqslant 128$.

Patients were admitted under a variety of consul-

Correspondence: J.T. Macfarlane, D.M., F.R.C.P. Accepted: 20 May 1991

tants and their management reflected the practice of the different firms involved. Statistical analysis was performed using Fisher's Exact Test.

\section{Results}

Of the 36 patients, 20 were male and 16 female. The population was elderly with a median age of 72.5 years (range 21-88); only 5 were under 50 years of age; $53 \%$ were current or recent smokers. The pre-existing diseases that were present in $75 \%$ are shown in Table I. The mortality was high with death in $14(39 \%)$. There was no difference in age or the incidence of pre-existing disease between survivors and non-survivors.

Amongst the 22 survivors, 17 were admitted with predominantly respiratory symptoms, in 7 complicating a preceding flu-like illness; the remainder were admitted with confusion (3), pyrexia (1), and diarrhoea (1). Amongst the 14 non-survivors admission was because of confusion in 6; respiratory symptoms in 5; diarrhoea 1; lethargy 1 and a perforated duodenal ulcer in 1. Overall, 'flu-like' symptoms were uncommon being present in only $12(33 \%)$ and these included: fever in $5(14 \%)$; sore throat in $5(14 \%)$; rigors in $4(11 \%)$; myalgia in 4 $(11 \%)$; gastrointestinal upset in $4(11 \%)$; and headache in $1(3 \%)$. There was no difference between survivors and non-survivors.

There were differences between survivors and non-survivors in respect of clinical and laboratory features as shown in Table II.

Other features which showed no difference between survivors and non-survivors included: 
Table I The presence of pre-existing disease amongst 36 adult patients with proven influenza

\begin{tabular}{lcr}
\hline Pre-existing disease & Number & $(\%)$ \\
\hline Previously well & 9 & $(25)$ \\
Respiratory & 17 & $(47)$ \\
Cardiac & 12 & $(33)$ \\
Cerebrovascular & 5 & $(14)$ \\
Diabetes mellitus & 3 & $(8)$ \\
Other & 1 & $(3)$ \\
\hline
\end{tabular}

Some patients had more than one pre-existing disease.

Table II Differences in symptoms, examination and laboratory tests between survivors and non-survivors of proven influenza

\begin{tabular}{|c|c|c|}
\hline & $\begin{array}{l}\text { Survivors } \\
(n=22)\end{array}$ & $\begin{array}{l}\text { Non-survivors } \\
\quad(n=14)\end{array}$ \\
\hline $\begin{array}{l}\text { Mean Age (years) } \\
\text { Anti-staphylococcal therapy }\end{array}$ & $\begin{array}{l}72 \\
17(77)\end{array}$ & $\begin{array}{l}72.5 \\
7(50)\end{array}$ \\
\hline $\begin{array}{l}\text { Symptoms } \\
\text { Cough } \\
\text { Discoloured sputum } \\
\text { Dyspnoea } \\
\text { Chest pain }\end{array}$ & $\begin{array}{r}20(91) \\
13(59) \\
19(86) \\
8(36)\end{array}$ & $\begin{array}{ll}6 & (43)^{*} \\
4 & (29) \\
6 & (43) \\
0 & (0)^{*}\end{array}$ \\
\hline $\begin{array}{l}\text { Examination } \\
\text { Confusion }\end{array}$ & $2(9)$ & $6(43)^{*}$ \\
\hline $\begin{array}{l}\text { Investigation } \\
\text { Lymphopenia } \\
\text { Plasma urea }>7 \mathrm{mmol} / 1\end{array}$ & $\begin{array}{l}8 / 21(47) \\
4 / 19(21)\end{array}$ & $\begin{array}{l}8 / 9(89)^{*} \\
8 / 11(73)^{*}\end{array}$ \\
\hline
\end{tabular}

Numbers in parentheses are percentages. As not all investigations were performed in all patients the number in whom it was performed is also shown. ${ }^{*} P<0.05$.

pyrexia in 20/36 (56\%); leucocytosis $13 / 33(39 \%)$; abnormal liver function tests $12 / 23(52 \%)$; and hypoalbuminaemia $6 / 22(27 \%)$. Focal chest signs were present in 24 patients $(67 \%)$ but radiographic abnormalities in only $14(39 \%)$. Wheeze was present in $17(47 \%)$.

Nineteen patients (53\%) had received no antibiotic therapy prior to admission. Eight patients, all of whom survived, received an aminopenicillin. Only 9 patients had received an antibiotic active against Staphylococcus aureus but there was no difference between survivors and non-survivors in this respect. Once admitted to hospital, antibiotic therapy was very variable: 14 different antibiotics were employed but only 24 patients received anti-staphylococcal cover; 11 of these had focal abnormalities on chest X-ray and 1 had $S$. aureus isolated from blood culture. There was no difference between survivors and nonsurvivors in this respect. Nineteen patients $(53 \%)$ received bronchodilator therapy for acute airflow obstruction; $15(42 \%)$ received systemic corticosteroids in addition. Two patients, both of whom died, received parenteral respiratory stimulants, and 4 patients, 3 of whom died, received intermittent positive pressure ventilation.

Bacterial pathogens were isolated in $12(33 \%)$ of patients. Not all investigations were performed in all patients. In the patients with Pseudomonas aeruginosa infection, 1 had cystic fibrosis and in the other 2 patients it was felt to be a late nosocomially acquired infection.

\section{Discussion}

These results afford only a partial glimpse of the impact of influenza in Nottingham. As they rely on retrospective analysis of case records and, indeed, also on the confirmation of influenza infection, they represent a highly selected sample. However, we feel that they do tell us something about how patients with proven influenza were managed during the period of a large and well publicized natural epidemic.

An attempt to make a positive diagnosis of influenza is made in only a few patients and whilst this may reflect the lack of an available specific therapy it also reflects on the under-investigation of patients with respiratory infection. Despite lower respiratory infection being common amongst this group of patients, blood cultures, serology and detection of pneumococcal antigen were performed in a minority. This is contrary to previous studies and guidelines that have emphasized the value of these tests. ${ }^{2,3}$

The role of Staphylococcus aureus as a secondary pathogen during influenza outbreaks has been emphasized in the past ${ }^{4}$ and strong recommendations regarding the use of anti-staphylococcal agents during influenza epidemics have been made. ${ }^{2,3}$ The evidence for a beneficial effect for such a policy is limited. In a large prospective study of pneumonia by the British Thoracic Society only 3 cases of $S$. aureus pneumonia occurred, all fatal. ${ }^{2}$ Comparing pathogens isolated during an influenza epidemic to those isolated during a non-epidemic year a 3-fold increase in $S$. aureus as a pathogen was seen and $33 \%$ of those infected died. ${ }^{4}$ Similar increased mortality from $S$. aureus has also been reported in other series. ${ }^{5,6}$ The high mortality of this often young ${ }^{4}$ group has lead to the recommendation that anti-staphylococcal cover be given during influenza epidemics. ${ }^{2,3}$

It is worrying, therefore, that such advice was not heeded and it emphasizes the need to ensure rapid institution and enforcement of antibiotic policies at such times. Districts should be encouraged to have a pre-planned policy that can be initiated at the first recognition of an influenza 
epidemic and disseminated rapidly to hospitals and the general practioners. In Nottingham, advice regarding appropriate antibiotic therapy during the epidemic was circulated to all staff; the poor response revealed by this survery perhaps suggests that a more aggressive approach needs to be adopted.

It is important to note that in this study 'flu' symptoms were uncommon and cannot be relied upon in deciding on the antibiotics to give patients with respiratory symptoms during epidemic periods. Importantly, influenza as a cause of confusion needs emphasis, particularly as this presentation of pneumonia is associated with a high mortality. $2,5,7$

Curwen and colleagues have estimated that a significant proportion of the excess deaths during an influenza epidemic are due to non-respiratory

\section{References}

1. Curwen, M., Dunnell, K. \& Ashley, J. Hidden influenza deaths. Br Med J 1990, 300: 896.

2. Scientific Committee of the British Thoracic Society. Community acquired pneumonia in adults in British hospitals in 1982-83: a survey of aetiology, mortality, prognostic factors and outcome. $Q J$ Med 1987, 62: 195-220.

3. Innes, J.A. Community acquired pneumonia. $\mathrm{Br} \mathrm{Med} J \mathrm{1989}$, 295: 1083-1084.

4. Schwarzmann, S.W., Adler, J.L., Sullivan, R.J. \& Marine, W.M. Bacterial pneumonia during the Hong Kong influenza epidemic of 1968-1969. Arch Intern Med 1971, 127: 1037-1041. causes. ${ }^{1}$ Our study revealed few cases of this but this almost certainly reflects the selected nature of this series. In order to study this proposition a prospective study with serological testing of all patients presenting to hospital would need to be undertaken.

In conclusion, we would like to stress again the importance of rapid and effective use of antibiotics during influenza outbreaks and the importance of providing adequate cover against $H$. influenzae, $S$. aureus and streptococcal infection.

\section{Acknowledgements}

We would like to thank all the clinicians of Nottingham for permission to study the case-notes of patients under their care.
5. Marrie, T.J., Durrant, H. \& Yates, L. Community-acquired pneumonia requiring hospitalization: 5 year prospective study. Rev Infect Dis 1989, 11: 586-599.

6. White, R.J., Blainey, A.D., Harrison, K.J. \& Clarke, S.K.R. Causes of pneumonia presenting to a district general hospital. Thorax 1981, 36: 566-570.

7. Starczewski, A.R., Allen, S.C., Vargas, E. \& Lye, M. Clinicat prognostic indices of fatality in elderly patients admitted to hospital with acute pneumonia. Age Ageing 1988, 17: 181-186 